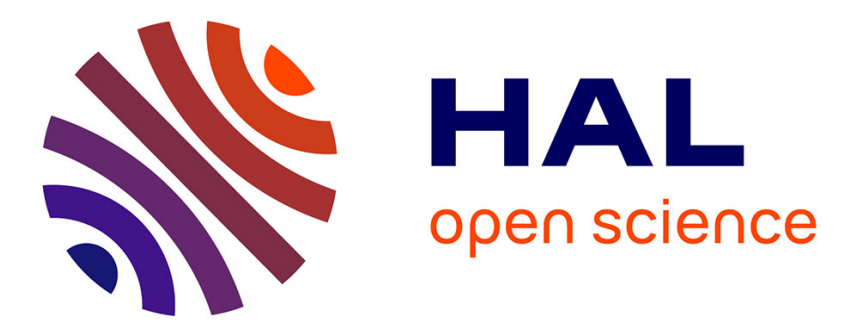

\title{
Digital image ratio: a new radiographic method for quantifying changes in alveolar bone. Part 1: theory and methodology
}

Alain Jean, Yves Epelboin, Alexandre Rimsky, Alain Soyer, Jean-Pierre Ouhayoun

\section{To cite this version:}

Alain Jean, Yves Epelboin, Alexandre Rimsky, Alain Soyer, Jean-Pierre Ouhayoun. Digital image ratio: a new radiographic method for quantifying changes in alveolar bone. Part 1: theory and methodology. Journal of Periodontal Research, 1996, 31 (3), pp.161-167. 10.1111/j.1600-0765.1996.tb00479.x . hal-01215512

\section{HAL Id: hal-01215512 \\ https://hal.science/hal-01215512}

Submitted on 24 Jun 2016

HAL is a multi-disciplinary open access archive for the deposit and dissemination of scientific research documents, whether they are published or not. The documents may come from teaching and research institutions in France or abroad, or from public or private research centers.
L'archive ouverte pluridisciplinaire HAL, est destinée au dépôt et à la diffusion de documents scientifiques de niveau recherche, publiés ou non, émanant des établissements d'enseignement et de recherche français ou étrangers, des laboratoires publics ou privés. 
Digital image ratio : a new radiographic method for quantifying changes in alveolar bone. Part I: Theory and methodology.

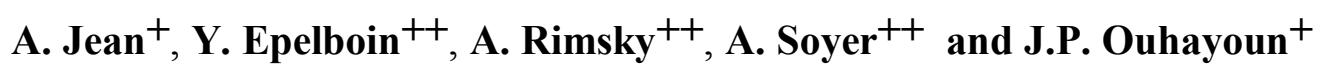

+Département de Parodontologie, Faculté de Chirurgie Dentaire, Université Paris VII, 5 rue Garancière, 75006 Paris

${ }^{++}$Laboratoire de Minéralogie-Cristallographie, UA 009 CNRS, Universités P.M. Curie et Paris VII, Case 115, 4 place Jussieu, 75252 Paris Cedex 05, France

Running title: Quantitative digital image ratio.

Address for reprints : Y. Epelboin.

Laboratoire de Minéralogie-Cristallographie, UA 009 CNRS, Universités P.M. Curie et Paris VII, Case 115, 4 place Jussieu, 75252 Paris Cedex 05, France

\begin{abstract}
A new method, digital image ratio (DIR), has been developed for directly measuring changes in alveolar bone. The image on the computer monitor represents the relative mass change between two radiographs. A Fourier filtering is used to reduce noise artefacts. This method is validated through an experiment with a step wedge. DIR needs only a preliminary calibration of the experimental conditions of operation and avoids tedious calibrations for each measurement as in the case of Digital Image Substraction. It is suggested to use low-voltage X-ray techniques for long-term quantitative studies of patients to minimise irradiation doses.
\end{abstract}

Theory and its validation are presented in a first part. A full clinical study appears in a second one.

Key words: Image filtering, image analysis, image ratio, bone radiography, quantitative digital radiography, quantification of bone changes. 


\section{INTRODUCTION}

There are two accurate methods for visualizing and measuring the changes in bone mass using two superimposable radiographs taken at two different times. The first, digital substraction radiography (DSR), has improved the diagnostic accuracy of dental radiology (1-8). The density of grey in the region of interest is converted into an equivalent thickness of the hydroxyapatite or aluminium standard. The density of the subtraction image can also be analysed by computer (CADIA), and the changes in the density of the alveolar bone are measured directly from the image (9). The second photodensitometric technique (10-11), requires a combination of photodensitometry and a computer to transform optical densities into aluminium-equivalent millimeters. However, neither technique is very convenient, since both require accurate calibration for each study. Moreover such conversions may introduce errors attributable to the heal effect and thus may not be warranted.

This study describes a new method based on the computation of the ratio of digitized radiographs. The resulting image, which is related to the mass ratio, directly shows the changes in bone mass. It is illustrated by the analysis of a few cases presented in a second part.

The main features of the method are shown in Figure 1.

\section{THEORY}

The analysis of a radiograph is the result of the following processes: exposure of the dental film, digitization of the radiographic image, measurement of the density of grey and calculation of the mass of the material whose changes are to be studied. In this section these different points are discussed. 


\section{Film exposure}

The probability of a photon interacting with the silver bromide or iodide grains in the photographic emulsion depends on the energy of the photons, i.e. on the wavelength of the beam. For each wavelength in the incident beam, we can write $(12,18)$ :

$$
D-f=D_{\max }(1-\exp (-k X))
$$

where $\mathrm{X}$ is the illumination (i.e. the number of photons) impinging on the film at a given wavelength, $\mathrm{k}$ a characteristic of the photographic emulsion, $\mathrm{D}_{\max }$ the maximum density capable of being recorded with the emulsion, i.e. a physical characteristic of the film. Its value varies between 4 and 6 , depending on the emulsion. D is the optical density of the film and exp is the exponential function. The minimum density is f, called the fog level, which value is of the order of 0.1-0.2. Figure 2 shows a typical curve: Figure $2 \mathrm{a}$ shows $\mathrm{D}$ versus $\mathrm{X}$, Figure $2 \mathrm{~b} \mathrm{D}$ versus $\log _{\mathrm{n}} \mathrm{X}$, which is the conventional plot. A plot of D versus $\log _{n} X$ (Fig. 2b) shows an area between $D_{a}$ and $\mathrm{Db}$ where the relationship between $\mathrm{D}$ and $\log _{\mathrm{n}} \mathrm{X}$ is linear:

$$
\mathrm{D}=\gamma \log \mathrm{X}+\mathrm{D}_{0}
$$

where $\mathrm{D}_{0}$ and $\gamma$ are constants. In all the calculations $\log _{n}$ means the natural logarithm. The parameters $f, D_{\max }$ and $\gamma$ depend on the physical characteristics of the film and on its processing (13). Standard working conditions must be defined.

\section{Digitizing the radiograph}

The optical density of grey, $\mathrm{D}$, is defined as:

$$
\mathrm{D}=\log _{\mathrm{n}} \frac{\mathrm{I} 0}{\mathrm{I}}
$$

where $\mathrm{I}_{0}$ is the intensity of the visible light impinging on the radiograph and $\mathrm{I}$ the intensity of the beam passing through. I, intensity of the visible light used when digitizing the radiograph, must not be confused with $\mathrm{X}$, the number of photons absorbed when recording the radiograph. The camera records the number of visible photons 
impinging on its detector. The value of a pixel is related to the intensity I thus a pixel value, in the digitized image, is directly related to the density of grey in the original radiograph (14).

Digitizing introduces noise, which limits the density of information, i.e. the number of levels which are distinguishable. It is always less than the maximum pixel value (14) and can be increased by summing videoframes (15). Noise artefacts are removed by filtering the images by means of Fourier transforms $(14,17)$.

\section{Measuring the absorbing mass in a radiograph}

Relationship between photoelectric absorption and absorbing mass: If $\mathrm{X}_{\mathrm{i}}$ is the illumination (number of X-ray photons) incident on an object and $\mathrm{X}$ is the illumination that passes through the object, then :

$$
X=X_{i} \exp \left(-\frac{\mu}{\rho} m\right)
$$

where $\mu / \rho$ is the mass absorption coefficient of the material for the considered wavelength and $m$ the total mass per unit of area lighted by the X-ray beam. $\mu / \rho$ depends on the material (16) (it is not the same for soft tissues, hydroxyapatite or calcium).

Equation (4) may be written as:

$$
\mathrm{m}=\frac{\rho}{\mu} \log _{n} \frac{X_{i}}{X}
$$

When digitizing a radiograph, the intensity I of the visible light going through the lens of the camera is recorded in the memory of the computer. According to equations (3) and (2) if the density of grey corresponds to the linear part of the densitometric curve:

and

$$
\log _{n} I=\log _{n} I_{0}-D
$$

$$
\mathrm{D}=\gamma \log \mathrm{X}+\mathrm{D}_{0}
$$


thus

$$
\log _{n} I=\log _{n} I_{0}-D_{0}-\gamma \log _{n} X
$$

From equations (5) and (6), it can be shown that:

$\mathrm{m}=\frac{\rho}{\mu}\left(\log _{n} X_{i}+\frac{1}{\gamma} \log _{n} I+\frac{D_{0}}{\gamma}-\frac{\log _{n} I_{0}}{\gamma}\right)=\frac{\rho}{\mu} \frac{1}{\gamma}\left(\log _{n} \alpha+\log _{n} I\right)$

where $\log _{n} \alpha=\gamma \log _{n} X_{i}-\log _{n} I_{0}+D_{0}$

is a constant for all radiographs recorded with the same experimental conditions for the $\mathrm{X}$-ray machine and digitised in the same conditions.

This equation is written for a single wavelength; we assume for the sake of simplicity that the constants do not vary significantly for the range of wavelengths produced by the X-ray machine.

The ratio technique: Two different cases must be considered. When the densities of grey correspond to the linear part of the densitometric curve (i.e. between 1.6 and 3 about as measured by Kodak for Ultraspeed and Ektaspeed films) equation (7) is valid. For lower values one must use equation (5) only.

Let us consider first equation (7) for two different radiographs, at points corresponding to the same location. $\mathrm{I}_{1}$ is the intensity passing through a given point in the first radiograph, I2 the intensity at the corresponding point in the second one.

$$
\mathrm{m}_{1}=\frac{\rho}{\mu} \frac{1}{\gamma}\left(\log _{n} \alpha_{1}+\log _{n} I_{1}\right) \mathrm{m}_{2}=\frac{\rho}{\mu} \frac{1}{\gamma}\left(\log _{n} \alpha_{2}+\log _{n} I_{2}\right)(8)
$$

We have measured that the value of a pixel $p$ in the memory of the computer is proportional to the logarithm of the intensity I impinging on the corresponding pixel of the camera CCD. Using a known optical standart (Zeiss Jena, Germany) which density varies from 0.1 up to 3.0 by steps of 0.1 we have plotted the pixel values of its digitized image versus the density value and we fund that:

$$
\mathrm{p}=\mathrm{a} \log _{n} \mathrm{I}+\mathrm{b}
$$


where $\mathrm{a}$ and $\mathrm{b}$ are two positive constants. This must be checked for other cameras and other experimental conditions. Thus equations (8) may be rewritten, replacing the intensity values I by the pixels values as:

$$
\frac{m_{2}}{m_{1}}=\frac{\left(a \log n \alpha_{2}-b\right)+p_{2}}{\left(a \log n \alpha_{1}-b\right)+p_{1}}=\frac{C_{2}+p_{2}}{C_{1}+p_{1}}
$$

Instead of computing the difference between the pixel values as in Digital Subtraction Radiography (DSR), we may use equation (10), which describes the ratio of the digitised images. This allows us to measure directly any changes in absorbing mass between two radiographs. The two-dimensional array $\mathrm{m}_{2} / \mathrm{m}_{1}$ for all pixels is called the "mass ratio image". It is an array of real numbers which can be normalised between 0 and 255 to be displayed in black and white or with pseudo-colors on the screen of a computer.

Let us now consider the case when the densities of grey are too small so that equation (2) is not valid. This occurs for densities lower than 1.6. From equations (3) and (9), one may write:

$$
\mathrm{D}=\log _{\mathrm{n}} \mathrm{I}_{0}+\frac{\mathrm{b}-\mathrm{p}}{\mathrm{a}}
$$

The constants are measured using a step wedge as explained later, in the validation section, thus the relationship between $\mathrm{p}$ and $\mathrm{D}$ is known. The relationship between $\mathrm{X}$, the X-Ray illumination and $\mathrm{D}$ may be tabulated from experimental measurements. In our case the curve has been provided by Kodak for the operating and development conditions used for the clinical studies. Using equation (5), equations (8) are replaced by:

$$
\begin{aligned}
& \mathrm{m}_{1}=\frac{\rho}{\mu}\left[\log _{1} X_{i}-\log _{1} X_{1}\right] \quad m_{2}=\frac{\rho}{\mu}\left[\log _{1} X_{i}^{\prime}-\log _{1} X_{2}\right] \\
& \text { which means: } \quad \frac{m_{2}}{m_{1}}=\frac{\log _{n} X_{i}^{\prime}-\log X_{2}}{\log _{n} X_{i}-\log X_{1}}=\frac{K_{2}-\log X_{2}}{K_{1}-\log X_{1}}
\end{aligned}
$$


Equation (12) is equivalent to equation (10) except that the relationship between the pixel value $\mathrm{p}$ and the illumination $\mathrm{X}$ is no more straightforward. Both $\mathrm{K}_{1}$ and $\mathrm{K}_{2}$ as well as $\mathrm{C}_{2}$ and $\mathrm{C}_{1}$ are constants which should be the same if the operating conditions remain unchanged between both radiographs. If not contrast adjustment may be necessary (appendix A). Other methods have been suggested by different authors $(19,24-26)$. The determination of these constants will be explained in the next section.

When computing the ratio between pixels values the noise is additive and thus enhanced in the resulting calculation. High frequency noise is removed by applying a low-pass filter in the Fourier space.

An advantage of digital image ratio (DIR) is that it is equally valid for both soft tissues and bone, since the absorption coefficient does not appear in equations (10) and (12).

\section{Validation}

To determine the constants $\mathrm{C}$ or $\mathrm{K}$ in equations (10) or (12) and to validate the method we use a step wedge (build in the laboratory) made of 10 areas. Each area is made of superposed layers of metal of equal thickness, thus the mass, in each area, is proportional to the number of layers. The step wedge is exposed to the X-Rays and the radiograph is developed in the same experimental conditions as used for the patients. The radiograph is then digitised twice, producing two images. The second image is shifted so that the same location in both images corresponds to different thicknesses. We study such areas to compute their mass ratio. Since the thicknesses, thus the masses are known this experiment allows to calculate $\mathrm{C}$ and to validate the method.

First it is necessary to verify equation (9) and to measure the constants appearing in equation (11). As explained before, this is done digitizing a known optical standard. It is then easy to measure precisely the optical densities for any radiograph. Such a calibration is made only once if the camera is always operated in the same conditions.

We have found that the measured densities for the radiograph vary from 0.2 which is to low to consider equation (10) thus we had to use equation (12). This means 
that $\mathrm{X}$ was determined from the measurement of the density $\mathrm{D}$ by means of the illumination curves provided by Kodak. This is computed automatically: the curves are registered in the computer which transforms the pixels values into optical densities using equation (11) then into $\log _{n} X$ using the tabulated curves.

Equation (12) may be written as:

$$
\mathrm{K}=\frac{\frac{\mathrm{m}_{2}}{\mathrm{~m}_{1}} \log _{\mathrm{n}} X_{1}-\log _{\mathrm{n}} X_{2}}{\frac{\mathrm{m}_{2}}{\mathrm{~m}_{1}}-1}
$$

$\mathrm{m}_{2} / \mathrm{m}_{1}$ is proportional to the thickness for each area, thus equal to the ratio of the number of layers of metal in each measured pixel. Table I gives the measured value for $\mathrm{K}$ in different areas and this together gives the constant needed in equation (12) and validates the method since this value is constant with a good accuracy. This constant is a characteristics of the operation conditions and is determined once only. It is necessary to re calibrate only if the exposure or development conditions are changed. Table II presents the results in a different manner. From table I a mean value for $\mathrm{K}$ has been calculated as -1.53 , then equation (12) is computed using this constant for different areas. This gives an idea of the accuracy of the method. It must be emphasised that the computer computes automatically the equation and presents the result as an image where the mass changes are directly visible. There is no need to compare the pixels values to a standard for each pair of radiograph as in DSR.

All explanations have been given using equation (12). The method is the same if the optical densities are high enough so that one must use equation (10). The constant $\mathrm{C}$ is determined as the constant $\mathrm{K}$. 


\section{DISCUSSION}

\section{Theoretical limitations}

We assume that the coefficients of equation (2) are the same for all wavelengths which is true (18).

The camera is assumed not to introduce any geometrical deformation, and the light used for the digitisation adjusted so that the dynamics of the camera is in the range where it is not saturated. It means that the illumination must be uniform in all the field of view and adjusted in a "reasonable range" nor to low nor to high. We have checked the characteristics of the camera as explained. If the response was not linear it would be possible to put the measured curve in the memory of the computer to correct this problem.

The mass ratio equation (10) or (12) are valid for a single wavelength $\lambda$ only. Far from an absorption edge, $\mu / \rho$ varies as $\lambda^{3}$. The X-Ray beam is polychromatic but all the calculations have been made for a monochromatic wave only since no analytical calculation would be possible otherwise. However since most of the energy is contained in the characteristics X-Ray emission wavelengths of the X-Ray tube this is a valid simplification which has been verified when validating the method. This simplification is acceptable for the wavelengths used in medical radiography (16).

By comparing areas without changes in various radiographs i.e. areas where the mass ratio should remain 1 , we have been able to estimate that the best precision is of the order of $5 \%$.

\section{The difference technique:}

Many authors (1-9) have computed the difference between two digitised images (DSR) to analyse changes in bone mass. After adjusting the contrasts between two radiographs, they compute the difference between the pixel values $\mathrm{p}_{2}$ and $\mathrm{p}_{1}$. This difference is a function of $\mu / \rho$ and does not consider separately the cases where the optical densities are either in the linear or non linear part of the densitometric curve. 
Quantitative information requires calibration with a standard. Moreover the standard is not the same for different tissues since the mass absorption coefficient $\mu$ is not the same. This is not true for DIR since $\mu$ is not present in equation (10) and (12).

We suggest that Fourier filtering could be used for DSR as we have done for DIR to eliminate the noise which is always additive.

\section{Influence of illumination geometry}

Like other methods, digital image ratio (DIR) is sensitive to variation in the illumination geometry because each pixel of the first radiograph is mapped into another pixel in the second radiograph. Thus the same conclusions are valid for DIR. We assume that a tilt of $\pm 2^{\circ}$ or $\pm 3^{\circ}$ is acceptable $(19,20)$.

\section{Operating parameters}

X-ray machines are usually operated between $70 \mathrm{kV}-90 \mathrm{kV}$ to obtain the best visual image contrast. Because the radiographs of this study are intended for digital methods, they do not need to be visually pleasing. The X-ray machine was operated at $50 \mathrm{kV}$. X-Rays absorbed by bone correspond to an energy range between $11.5 \mathrm{keV}$ and $23 \mathrm{keV}$ (fig. 3). When operating the $\mathrm{X}$-Ray machine at $50 \mathrm{kV}$ the maximum intensity $\mathrm{X}$ corresponds to an energy of $22.8 \mathrm{keV}$ which is the upper limit of the absorbed energy. Increasing the voltage mainly shifts the emitted energy spectrum to higher energy. Thus it is useless to operate the tube at a higher voltage. Increasing the voltage also increases the diffuse scattering which appears as background in the image and is a source of error for a quantitative measurement $(21,22)$. The sensitivity of the X-ray films decreases when the energy of the photons increases since the most energetic photons pass through. According to Okano (23) a Kodak D film exposed at $70 \mathrm{kV}$ has a scattering section of 0.1 , i.e. $10 \%$ of the photons only are absorbed. It is not efficient to use a too energetic radiation. 


\section{CONCLUSION}

DIR does not suffer from certain difficulties encountered in other methods (811) for comparing superimposable radiographs. Diffuse scattering arising from soft tissues and other dental structures need not be taken into account, as it is the same for a given patient and site. The spectral emission characteristics of the X-ray tube are not important, as long as the same machine operating in the same conditions is used. The numerical noise, which is a major source of errors, is removed by multiple acquisition and Fourier filtering.

DIR has the advantages of showing the density of matter by displaying directly the mass ratio. DIR is a simple method which can be used for long-term studies. It combines the advantages of low X-ray machine voltage $(50 \mathrm{kV})$ and short exposure times, making it possible to study several sites on the same patient with lower irradiation doses.

DIR has been successful to measure bone change. A full clinical study is presented in part II which validates this new method.

\section{Acknowledgements}

Part of this work was financially supported by the Scientific Committee of Faculty of Dental Surgery, University Paris 7- Garancière.

The authors acknowledge M. Pilard and F. Morris for their help and fruitful discussion. They thank Dr J. Härtwig (European Synchrotron Radiation Facility, Grenoble) for providing the optical standard and G.Villard and D.Guillet from Kodak for providing the illumination curves. 


\section{References}

1. Gröndahl HG, Gröndahl K. Subtraction radiography for the diagnosis of periodontal bone lesions. Oral Surg 1983; 55: 208-213

2. Ortman LF, Dunford R, Mc Henry K, Hausmann E. Subtraction radiography and computer assisted densitometric analysis of standardized radiographs. J Periodont Res 1985; 20: 644-651.

3. Gröndahl K, Gröndahl HG, Wennström J, Heijl L. Examinater agreement in estimating changes in periodontal bone from conventional and subtraction radiograph. J Clin Periodontol 1987; 14: 74-79.

4. Hausmann E, Dunford R, Wikesjö U, Christersson L, McHenry K. Progression of untreated periodontitis assessed by subtraction radiography. J Periodont Res 1986; $21: 716-721$.

5. Hausmann E, Christersson L, Dunford R, Wikesjö U, Phyo J, Genco RJ. Usefulness of subtraction radiography in the evaluation of periodontal therapy. $J$ Periodont Res 1986; 21: 716-721.

6. Schmidt E, Loesche W, Webber R. Effect of periodontal therapy on alveolar bone as measured by subtraction radiography. J Dent Res 1986; 65: AADR, 525, 228.

7. Vos MH, Janssen PT, van Aken J, Heethaar RM. Quantitative measurement of periodontal bone changes by digital subtraction. J Periodont Res 1986; 21: 583591.

8. Webber RL, Ruttimann UE, Heaven TJ. Calibration errors in digital subtraction radiography. J Periodont Res 1990; 25: 268-275.

9. Brägger D, Pasquali L, Rylander H, Carnes D, Kornman KS. Computer assisted densitometric image analysis in periodontal therapy. A methodological study. $J$ Clin Periodontol 1988; 15: 27-37.

10. Omnell KA. Quantitative roentgenologic studies on changes in mineral content of bone in vivo. Acta Radiologica 1957; (suppl. 148): 2-86. 
11. Payot P, Haroutunian B, Pochon Y, Herr P, Bickel M, Cimasoni G. Densitometric analysis of lower molar interradicular areas in superposable radiographs. J Clin Periodontol 1987; 14: 1-7.

12. Hirsch FR. The Blackening of Photographic Plates by Long Wavelength X-Rays. J. Opt. Soc. Amer. 1935; 25: 229-230.

13. Epelboin Y, Jeanne-Michaud A, Zarka A. The Use of Nuclear Emulsions in X-ray Topography: Improvement of the Development Methods. J. Applied Cryst. 1979; 12: $201-204$.

14. Buseck P, Epelboin Y, Rimsky A. Signal Processing of High-Resolution Transmission Electron Microscope Images Using Fourier Transforms. Acta Cryst. 1988; A 44: 975-986

15. Tanner B.K., Cringean J.K. Real Time and Stroboscopic Topography. Prog. Cryst. Growth 1987; 14: 403-424

16. International Tables for X-Ray Crystallography. Birmingham: Kynoch Press, 1974; IV: 47-70.

17. Gonzales RC, Wintz P. Digital Image Processing. 2nd ed. Addison-Wesley, 1987: $61-136$.

18. Morimoto H, Uyeda R. A Second Comparison of Various Commercially Available X-ray Films. Acta Cryst. 1963; 16: 1107-1119.

19. Ruttimann UE, Okano T, Grondahl H-G, Grondahl K, Webber RL. Exposure geometry and film contrast differences as bases for incomplete cancellation of irrelevant structures in dental subtraction radiography. 1981; Proceedings of SPIE. 314: 372-377.

20. Grondahl K, Grondahl H-G, Webber RL. Influence of variations in projection geometry on the detectability of periodontal bone lesions. A comparaison between subtraction radiography and conventional radiographic technique. $J$ Clin Periodontol 1984; 11: 411-420.

21. Webber RL, Tzukert A, Ruttimann U. The effects of beam hardening on digital subtraction radiography. $J$ Periodont Res $1989 ; 24: 53-58$ 
22. Janssen, PTM, van Aken, J. Problems around the in vitro and in vivo application of quantitative digital subtraction radiography. J Clin Periodontol 1989; 16: $323-$ 330.

23. Okano T, Grondahl H-G, Grondahl K, Webber RL. Effect of quantum noise on the detection of incipient proximal caries. Oral surgery, Oral Medicine, Oral Path. 1982; 53: 212-218.

24. Fourmousis I, Brägger U., Bürgin W., Tonetti M., Lang NP. Digital Image Processing: I Evaluation of grey level correction methods in-vitro. Clin. Oral Impl. Res. 1994; 5: 37-47

25. Ohki M., Okano T., Yamada N. A contrast correction method for digital substraction radiography. J. Periodont. Res. 1988; 23: 277-280

26. Ruttiman UE., Webber RL., Schmidt E. A robust digital method for film contrast correction in substraction radiography. J. Periodont. Res. 1986; 21: 486-495 


\section{Appendix A}

\section{Contrast adjustment}

Let p1 (i) be the density of a pixel in the first image, p2 (i) the density of the pixel in the second image at the same location $\mathrm{i}$. The image contains $\mathrm{N}$ pixels, numbered from $\mathrm{i}=1$ to $\mathrm{i}=\mathrm{N}$. In the present case $\mathrm{N}=512 * 512$.

We compute:

$$
\overline{p_{1}}=\frac{1}{N} \sum_{i=1}^{N} p_{1}(i) \quad \text { and } \overline{p_{2}}=\frac{1}{N} \sum_{i=1}^{N} p_{2}(i)
$$

$\overline{\mathrm{p}} 1$ and $\overline{\mathrm{p}} 2$ are the mean densities of the images. If changes occur in limited areas only, computing the densities in the whole image does not introduce significant errors. Otherwise these statistics must be computed from areas where one is sure that no change occurs.

Then we compute the variances :

$\sigma_{1}=\frac{1}{N} \sum_{i=1}^{N}\left(p_{1}(i)-\overline{p_{1}}\right)^{2} \quad$ and $\quad \sigma_{2}=\frac{1}{N} \sum_{i=1}^{N}\left(p_{2}(i)-\overline{p_{2}}\right)^{2}$

The relation between the densities of the pixels is linear, since it corresponds to the linear part of the densitometric curve:

$$
\mathrm{p}_{2}(\mathrm{i})=\mathrm{a} \cdot \mathrm{p}_{1}(\mathrm{i})+\mathrm{b}
$$

thus:

$$
a=\sqrt{\frac{\sigma_{2}}{\sigma_{1}}} \quad \text { and } \quad b=\bar{p} 2-\sqrt{\frac{\sigma_{2}}{\sigma_{1}}} \bar{p} 1 \text {. }
$$

This is a statistical method where all the pixel values are modified through a linear equation. The information in the image is not modified. Other methods such as histogram equalisation modify locally the pixel values and the information is irreversibly changed. The image may looks nicer but becomes quantitatively wrong. 


\begin{tabular}{c|c|c|c|c}
$\mathrm{m}_{2} / \mathrm{m}_{1}$ & $2 / 3$ & $7 / 10$ & $9 / 7$ & $4 / 3$ \\
\hline $\mathrm{K}$ & -1.45 & -1.55 & -1.57 & -1.55
\end{tabular}

Table 1. Values of the constant K (equation (12)) as calculated from different areas of the step wedge. First line: value of the mass ratio, second line: constant as calculated from equation (13).

\begin{tabular}{c|c|c|c|c}
$\mathrm{m}_{2} / \mathrm{m}_{1}$ theo. & $2 / 3$ & $7 / 10$ & $9 / 7$ & $4 / 3$ \\
\hline $\mathrm{m}_{2} / \mathrm{m}_{1}$ calc. & 0.65 & 0.69 & 1.28 & 1.32
\end{tabular}

Table 2. True mass ratio and corresponding calculated mass ratio for different areas of the step wedge, using the mean value from table 1 for $\mathrm{K}$. 


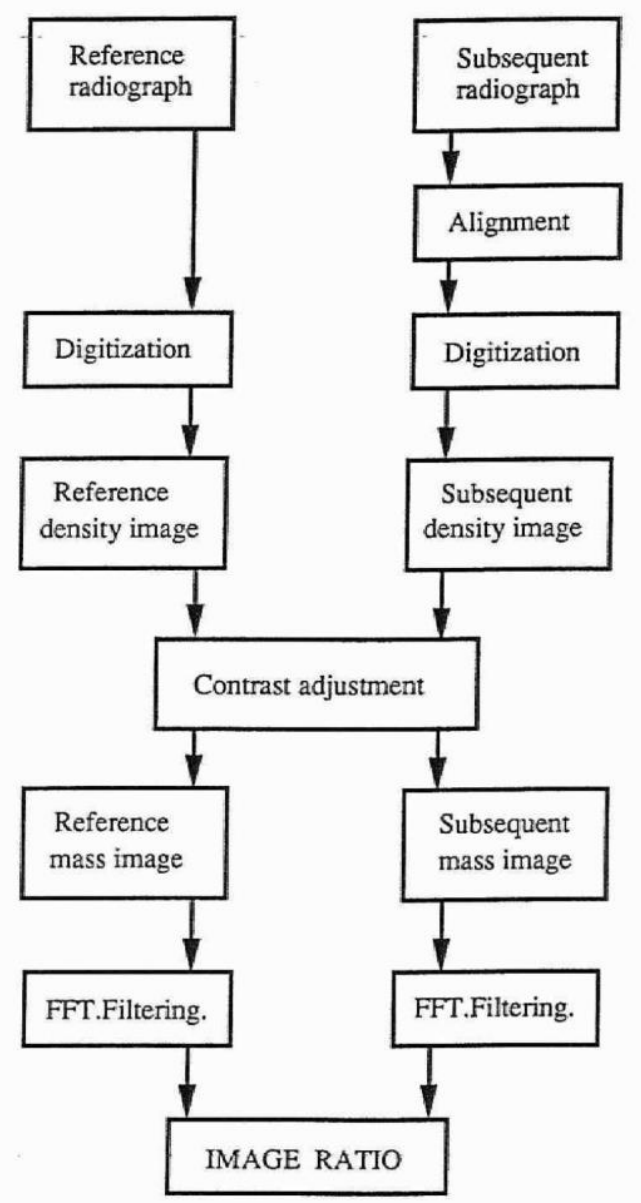

Fig. 1. Flowchart of the digital image ratio method (DIR). 


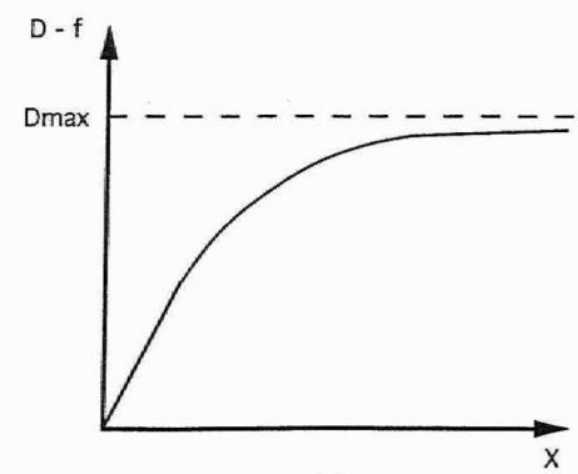

(a)

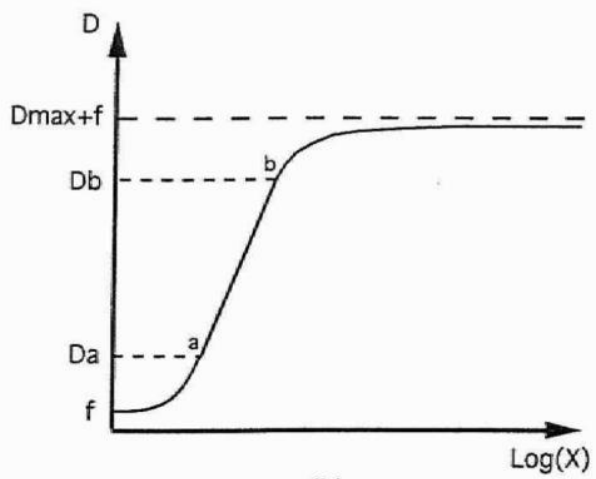

(b)

Fig. 2. Typical response of a photographic emulsion.

(a) Density of grey versus the intensity of the incident beam.

(b) Same curve plotted on a logarithmic scale.

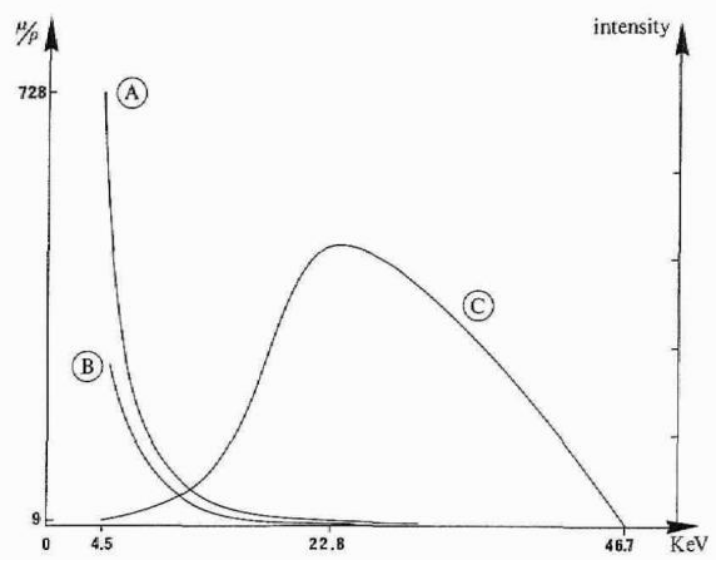

Fig. 3 (A) Change in the mass absorption coefficient of calcium as a function of the incident X-Ray beam energy.

(B) Same curve for hydroxyapatite

(C) Spectral distribution of X-Ray radiation for a machine operating at $50 \mathrm{kV}$. 